\title{
Endemik Stachys pumila Banks \& Sol. ve Stachys citrina Boiss. \& Heldr. (Lamiaceae) Türleri Üzerine Karşılaştırmalı Anatomik ve Mikromorfolojik Bir Çalışma
}

\author{
Muhittin DINÇ⿻1 ${ }^{1}$, Mustafa İÇEL $\dot{\mathbf{I}}^{1}$, Süleyman DOĞ $\mathbf{U}^{2, *}$ \\ ${ }^{1}$ Necmettin Erbakan Üniversitesi, Ahmet Keleşoğlu Eğitim Fakültesi, Biyoloji Eğitimi, \\ KONYA \\ ${ }^{2}$ Necmettin Erbakan Üniversitesi Meram Meslek Yüksekokulu, Bitkisel ve Hayvansal Üretim \\ Bölümü, KONYA \\ * suleymandogu@gmail.com
}

\begin{abstract}
Öz: Bu çalışmada, Türkiye'de yayılış gösteren Infrarosularis Bhattacharjee seksiyonuna ait endemik Stachys pumila Banks ve Sol., S. citrina subsp. citrina ve S. citrina subsp. chamaesideritis taksonları, anatomik ve mikromorfolojik olarak çalışılmış ve karşılaştırılmıştır. Her üç taksona ait Türkiye'nin farklı yerlerinden toplanan örnekler çalışmanın materyalini teşkil etmiştir. Toplanan örneklerin bir kısmı herbaryum materyali haline getirilirken, bir kısmı da \%70’lik alkol içinde muhafaza edilmiştir. Anatomik çalışmalar için alkol içindeki örneklerden manuel olarak gövde ve yaprak enine kesitleri ile yaprak yüzeysel kesitleri alınmış ve daimi preparat haline getirilmiştir. Anatomik deskripsiyonlar ve tüy morfolojileri daimi preparatların incelenmesi ve çekilen fotoğrafların değerlendirilmesi ile yapılmıştır. Çalışmadan elde edilen sonuçlar, anatomik karakterler ve tüy morfolojisi karakterlerinin yakın akraba türler olan $S$. citrina ile $S$. pumila'nın taksonomik sınıflandırılmasında değere sahip olduğunu, fakat $S$. citrina'nın alt türlerinin ayrımında değerlerinin sınırlı olduğunu göstermiştir.
\end{abstract}

Anahtar Kelimeler: Anatomi, Stachys pumila, Stachys citrina, taksonomi, tüy, Türkiye.

\section{Comparative Anatomical and Micromorphological Study on Turkish Endemic Stachys pumila Banks \& Sol. and Stachys citrina Boiss. \& Heldr.}

\begin{abstract}
In this study, Stachys pumila Banks \& Sol., S. citrina subsp. citrina and S. citrina subsp. chamaesideritis included in sect. Infrarosularis Bhattacharjee were studied anatomical and micromorphological point of view and compared each other. The samples belong to the taxa which were collected from different localities in Turkey were composed of the study materials. When some materials were kept in $70 \%$ alcohol, the rests were preserved as herbarium samples. For the anatomical studies, the cross-sections of leaf and stem along with the surface sections of leaf were manually obtained from the samples in the alcohol, and the permanent preparats were arranged. Anatomical descriptions and determinations of the trichome morphologies were made by the observation of the permanent preparats and the evaluation of the photos. The results obtained from the present study, the anatomical characters along with the morphological and trichome have taxonomic value in delimitation of S. pumila and S. citrina, but they have limited taxonomic importance in separation of the subspecies of S. citrina.
\end{abstract}

Keywords: Anatomy, Stachys pumila, Stachys citrina, taxonomy, trichome, Turkey.

\section{Giriş}

Lamiaceae (Labiatae) familyas 1 bitkileri Kuzey Kutbu’ndan Himalayalar’a, Güney Doğu Asya'dan Havai ve
Avustralya'ya, Afrika ve Amerika'ya kadar geniş bir alanda yetişmekle birlikte, özellikle Akdeniz Bölgesi'nde oldukça yoğun bir yayılışa sahiptir. Dünya üzerinde 224 cins 
ve yaklaşık 5600 tür ile temsil edilen kozmopolit bir familyadır. Türkiye Florası'nda ise Lamiaceae familyası 45 cins, 565 tür ve toplam 735 takson ile temsil edilmektedir (Duman ve ark., 2005).

Stachys L. içerdiği 300 civarındaki tür ile Lamiaceae familyasının en büyük cinslerinden biridir. Bu cins, kozmopolit olup Akdeniz ve Güneybatı Asya'nın 1lıman bölgelerinde merkezlenmiş, ikincil yayılış merkezleri olarak da Kuzey ve Güney Amerika ile Güney Afrika göze çarpmaktadır. Tür sayısı bakımından cinsin iki merkezi bulunmaktadır. Birisi Güney ve Doğu Anadolu, Kafkasya, Kuzeybatı İran ve Güney Irak'1 içine alan bölge, diğeri ise Balkan Yarımadası'dır. Cinsin türlerinin büyük çoğunluğu kayalık alanlarda, özellikle de kalker kayalıklarda yayılış göstermektedir (Bhattacharjee, 1980).

Stachys cinsi, Türkiye Florası'nda Bhattacharjee (1982) tarafindan revize edilmiştir. Bu çalışmaya göre cins, Türkiye Florası'nda 12 alt seksiyon, 15 seksiyon ve 2 alt cinse mensup 72 tür ile temsil edilmektedir (Bhattacharjee, 1982). Bu türlerden 6 tanesini içeren Infrarosularis seksiyonu, 7 takson içermektedir.

Davis ve ark. (1988), Türkiye Florası'nın 10. ek cildinde, Stachys choruhensis, Stachys antalyaensis, Stachys chasmosericea, Stachys tundjeliensis türlerinin Türkiye Florası'na katıldığını rapor etmişlerdir. Bunlardan Stachys choruhensis'in Infrarosularis seksiyonuna katılımıyla seksiyondaki tür sayısı 7'ye, takson sayısı 8'e çıkmıştır.

Duman (2000), Türkiye Florası'nın ek 11. cildinde, Stachys cydni ile birlikte Türkiye Florası için 5 Stachys türünün daha belirlendiğini rapor etmiştir. $\mathrm{Bu}$ türler: $S$. anamurensis, S. sivasica, S. baytopiorium, $S$. willemsei, S. cydni'dir. Bunlardan $S$. anamurensis, S. sivasica, S. willemsei, S. cydni türleri endemiktir. Son zamanlarda yapılan çalışmalarda Stachys cinsine mensup 5 takson daha tanımlanmıştır (Dinç ve Doğan, 2006; İlçim ve ark., 2008; Daşkın ve ark., 2009; Akçiçek, 2010). Bunlardan Stachys marashica ve S. gaziantepensis'in Infrarosularis seksiyonuna katılımıyla seksiyondaki tür sayısı 9'a çıkmıştır (Akçiçek 2012).

Son zamanlarda, tohumlu bitkilerin taksonomisinin daha iyi anlaşılabilmesi ve birçok grupta var olan taksonomik problemlerin çözülebilmesi için, klasik morfolojik verileri destekleyebilecek farklı parametreler üzerinde çalışmalar yapılmaya başlanmıştır. Bunlardan anatomik ve mikromorfolojik karakterler en yoğun olarak çalışılan parametreler arasındadır. Anatomik karakterlerin bitki taksonomisindeki potansiyel önemi eskiden beri bilinmektedir (Metcalfe ve Chalk, 1950, 1983).

Ülkemizdeki Lamiaceae familyasının değişik cinslerine ait türler üzerinde yapılmış çok sayıda anatomik çalışma 
bulunmaktadır. (Kahraman ve ark., 2009, 2010a ve b; Özdemir ve Şenel, 1999-2001; Baran ve Özdemir, 2009; Dinç ve ark., 2008a, ve b, 2009, 2011; Güvenç ve Duman, 2010; Özcan ve Ağaoğlu, 2014; Demirelma ve ark., 2018). Bununla birlikte Stachys cinsi üzerine yapılan anatomik çalışmalar kısıtlıdır (Uysal, 2002, 2003; Dinç ve Öztürk, 2008a).

Lamiaceae familyasına ait bitkiler genellikle bütün yüzeylerinde tüylere sahiptir. $\mathrm{Bu}$ tüyler hem örtü hem de salg1 tüyleri şeklindedir. $\mathrm{Bu}$ bitkilerin başlıca salg1 organı olan salg1 tüyleri generatif organlarda da bulunabilmektedir (Mihalik, 1992). Familya üyelerinde çok hücreli başlı kapitat salgı tüylerinin yanında değişik tipte tüylere de rastlanmaktadır (Özörgücü ve ark., 1991; Özdemir ve Şenel, 1999). Lamiaceae familyasında, tüylerin taksonomik değeri ve filogenetik ilişkileri açısından sistematik önemi iyi bilinmektedir (Abu Assab ve Cantino, 1987). Tüy, familyaya ait bazı cinsler için çok önemli taksonomik karakterler arasında yer almaktadır. Lamiaceae familyasına ait farklı cinsler üzerinde tüy morfolojisi ile ilgili çalışmalar bulunmaktadır (Satıl ve Kaya, 2007; Sat1l ve ark., 2011).

Sadece klasik morfolojiye göre yapılan sinıflandirmalarda kesin olarak çözümlenemeyen taksonomik problemler, son dönemlerde modern taksonomik parametrelerin kullanılmasıyla çözümlenebilir duruma gelmiştir. $\mathrm{Bu}$ parametrelerden anatomik ve mikromorfolojik özellikler de sıklıkla kullanılmaktadır. Bazı bitki gruplarında özellikle de Lamiaceae familyasında anatomik ve mikromorfolojik karakterlerin kullanımı, sınıflandırma ile ilgili belirsizliklerin giderilmesinde çok önemlidir. Stachys cinsi üzerine yapılmış bazı anatomik ve mikromorfolojik araştırmalar olmasına rağmen, çalışılan endemik türler için böyle çalışmalara rastlanmamıştır. $\mathrm{Bu}$ çalışmanın amacı, endemik Stachys pumila ile yakın akrabası Stachys citrina'ya bağlı alt türler olan Stachys citrina subsp. citrina ve Stachys citrina subsp. chamaesideritis alt türlerinin anatomik ve mikromorfolojik özeliklerini ortaya koymaktır.

\section{Materyal ve Yöntem}

Çalışma kapsamındaki Stachys citrina subsp. citrina, Stachys citrina subsp. chamaesideritis ve Stachys pumila taksonlarına ait hem çiçekli hem de meyveli örnekler, Türkiye Florası'ndaki yayılış verilerine dayanarak, Türkiye'nin farklı yerlerinden toplanmıştır. Materyallerle ilgili toplama verileri Çizelge 1'de, toplama lokaliteleri de Şekil 1'de sunulmuştur. Üç taksona ait toplanan örneklerin bir kısmı standart yöntemlere göre kurutularak herbaryum materyali haline getirilmiştir. $\mathrm{Bu}$ materyallerin bir kısmı, çalışma kapsamında 
yapılacak olan mikromorfolojik

çalışmalarda kullanılmıştır.

Çizelge 1. Stachys citrina subsp. citrina ve Stachys citrina subsp. chamaesideritis ve Stachys pumila taksonlarının toplama bilgileri

Takson S. citrina subsp.
citrina

S. citrina subsp. chamaesideritis

S. pumila
Lokalite Toplayıc Bilgileri

C4 KONYA: Taşkent, Balcılar, Tülek Dağı, 2000 m, 03.07.2009

B6 KAYSERİ: Aslantaş. Kayalık yamaçlar,1900 m, 03.07.2009

C6 HATAY: Antakya, St. Peter

Kilisesi civarı, kayalık yamaçlar, $100 \mathrm{~m}, 07.07 .2010$

\section{M.Dinç 3321 ve S. Doğu}

M.Dinç 3203 ve S. Doğu

Y.Bağcı 3810 ve M.Dinç

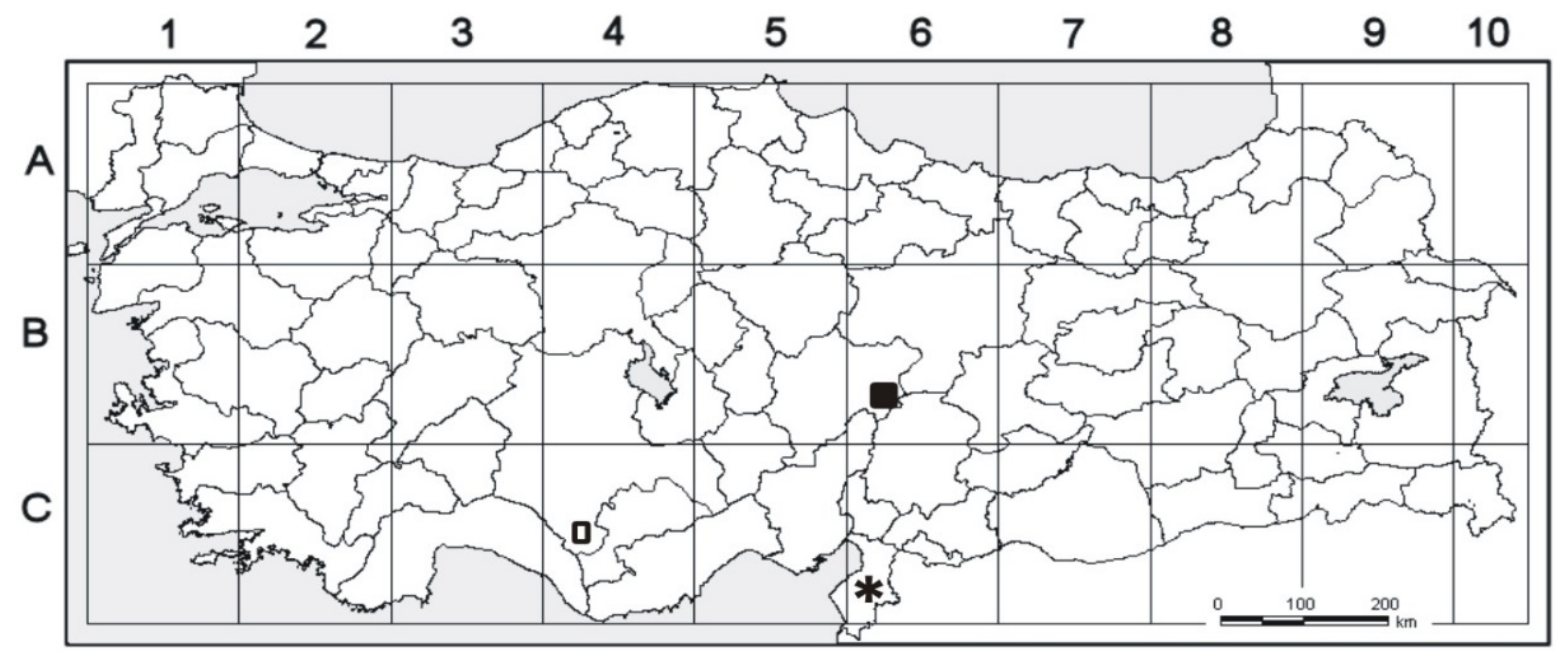

Şekil 1. Çalışılan taksonların toplama lokalitelerini gösteren harita ( $\square)$ S. citrina subsp. citrina,

(a) S. citrina subsp. chamaesideritis, (*) S. pumila

Her üç türe ait toplanan örneklerin bir kısmı anatomik çalışmalarda kullanılmak üzere içinde $\% 70$ alkol bulunan kavanozlara alınmış ve kavanozlar etiketlenerek 1 şık almayan bir dolapta saklanmıştır. Anatomik çalışmalarda, jilet yardımıyla manuel olarak her üç taksona ait en az yirmişer tane gövde ve yaprak enine kesiti ile yaprak alt ve üst yüzeysel kesitleri alınmış ve daimi preparatlar halinde hazırlanmıştır. Daimi preparatlar hazırlanırken, vasat malzemesi olarak enine kesitler için bazik fuksinli gliserin-jelatin, yüzeysel kesitler için gliserin-jelatin kullanılmıştır (Vardar, 1987). 
Hazırlanan preparatlar, Olympus BX- 50 marka $1 s ̧ 1 \mathrm{k}$ mikroskobuyla incelenerek gerekli ölçümler alınmış ve her üç takson için anatomik deskripsiyonlar hazırlanmıştır. Taksonlara ait her bir preparasyon için Olympus BX-50 marka mikroskoba bağlı "kameram" aparatından faydalanmak suretiyle fotoğraflar çekilmiş ve en iyi temsili fotoğraflar çalışmada sunulmuştur.

Yapraklar için stoma indeksi ve indeks oranları Meidner ve Mansfield (1968)'e göre tayin edilmiştir. Stoma indeksinin belirlenebilmesi için bitkinin aynı yaştaki yapraklarının alt ve üst yüzeylerinde 1 $\mathrm{mm}^{2}$,ye düşen stoma ve epidermis hücresi adedi, oküler mikrometre ile sayılmıştır. Taksonların yaprak alt ve üst yüzeyleri için stoma indeksi ve stoma indeks oranları, Meidner ve Mansfield (1968)'e göre hesaplanmıştır.

Çalışılan taksonlardaki tüy morfolojisi de ayrıntılı olarak tanımlanmıştır. Bunun için her üç taksonun yaprak ve gövdelerinden ortalama yirmişer adet enine kesit alınmış ve bu kesitler Olympus BX-50 marka 1şık mikroskobu ile taranarak, çalışılan taksonlardaki farklı tüy morfolojileri belirlenmiştir. Daha sonra her takson için gövde ve yaprakta bulunan tüyler kaydedilerek tablo halinde sunulmuştur. Tüy morfolojilerinin tanımlanması Uphoff (1962)'a, Metcalfe ve Chalk (1972)'e, Payne (1978)'ye, Bini Maleci ve Servettaz (1991)’a, Navarro ve El Oualidi (2000)’ye göre yapılmıştır.

\section{Bulgular \\ 3.1. Gövde Anatomisi}

Gövde enine kesitinin genel görünümü, S. pumila' da belirgin şekilde dört köşeli iken, S. citrina subsp. citrina ve $S$. citrina subsp. chamaesideritis'te belirgin şekilde dört köşeli olmayıp yuvarlağımsıdır (Şekil 2). Epidermis tek sıralı karemsi, dikdörtgenimsi ve yumurtamsı hücrelerden ibaret olup, üzeri kalın bir kutikula tabakası ile kaplanmıştır. Epidermis üzerinde glandular ve glandular olmayan yoğun tüyler bulunmaktadır. Glandular tüyler peltat, kısa kapitat ve uzun kapitat; glandular olmayan tüyler uzun kamçımsı, kısa ve uzun asikular (biz) şeklindedir. Kısa asikular tüyler k1sa tek hücreli, uzun asikular tüyler 2-6 hücrelidir.

S. pumila'da gövde köşelerinde epiderma altında son derece iyi gelişmiş, kalın çeperli 9-11 sıra hücrelerden oluşan kollenkima tabakası bulunmaktadır. $S$. citrina subsp. citrina ve $S$. citrina subsp. chamaesideritis'te ise gövde köşelerindeki kollenkima 5-7 sıra hücreden oluşmaktadır (Çizelge 2). S. pumila'da köşelerde bulunan kalın kollenkima tabakası gövde köşelerinde belirgin bir çıkıntı oluşumuna neden olurken, $S$. citrina subsp. citrina ve $S$. citrina subsp. chamaesideritis'te belirgin bir çıkıntı oluşturmadığından gövde 
yuvarlağımsıdır. Kollenkima tabakası yumurtamsıdır. Bununla birlikte, korteks gövdenin diğer kısımlarında ancak 1-2 parankiması hücrelerine göre ileri derecede sıradır. Kollenkima ile endodermis arasında bir farklılaşma göstermemişlerdir. 5-10 tabaka dikdörtgenimsi ve yuvarlak Endodermis altında iletim demetlerine hücrelerden oluşan korteks tabakası rastgelen kısımlarda sklerankimatik perisik1 bulunmaktadır. Korteks tabakası hücreleri, tabakası bulunmaktadır. Bu tabaka iletim genel olarak kloroplast içermediklerinden veya çok az içerdiklerinden saydam görünüme sahiptirler. Korteks altında tek s1ra hücrelerden oluşan endodermis tabakası bulunmaktadır. Endodermisi oluşturan demetleri üzerinde hilâl şeklinde olup iletim demetlerini diştan çevrelemiştir. Sklerankimatik perisikl tabakası $S$. pumila'da 2-3 sıra hücreden oluşurken, $S$. citrina subsp. citrina ve S. citrina subsp. hücreler düzenli sıralanmıș ve chamaesideritis'te 4-6 sıralıdır (Tablo 2).

Çizelge 2. Stachys citrina subsp. citrina, Stachys citrina subsp. chamaesideritis ve S. pumila taksonlarının anatomik ve mikromorfolojik olarak karşılaştırması

\begin{tabular}{|c|c|c|c|}
\hline & S. citrina subsp. citrina & $\begin{array}{l}\text { S. citrina subsp. } \\
\text { chamaesideritis }\end{array}$ & S. pumila \\
\hline Gövde & $\begin{array}{l}\text { Köşelerde 5-7 sıra kollenkimalı, } \\
\text { yuvarlağımsı, sklerankimatik } \\
\text { perisikl 4-6 tabakalı. }\end{array}$ & $\begin{array}{l}\text { Köşelerde 5-7 sıra kollenkimalı, } \\
\text { yuvarlağımsı, sklerankimatik } \\
\text { perisikl 4-6 tabakalı. }\end{array}$ & $\begin{array}{l}\text { Köşelerde } 9-11 \quad \text { sıra } \\
\text { kollenkimalı, belirgin köşeli, } \\
\text { sklerankimatik perisikl } 2-3 \\
\text { tabakall. }\end{array}$ \\
\hline $\begin{array}{l}\text { Yaprak } \\
\text { mezofili }\end{array}$ & $\begin{array}{l}\text { İzolateral (ekvifasiyal), \% } 75- \\
80 \text { palizat, \% 20-25 sünger } \\
\text { parankimasından oluşmuş. }\end{array}$ & $\begin{array}{l}\text { İzolateral (ekvifasiyal), \% } 75- \\
80 \text { palizat, \% 20-25 sünger } \\
\text { parankimasından oluşmuş. }\end{array}$ & $\begin{array}{l}\text { Dorsiventral (bifasiyal), } \% \\
60-65 \text { palizat, \% } 35-40 \\
\text { sünger parankimasından } \\
\text { oluşmuş. }\end{array}$ \\
\hline $\begin{array}{l}\text { Yaprak } \\
\text { orta } \\
\text { damarı }\end{array}$ & $\begin{array}{l}\text { Mezofile göre ortalama } 3 \text { kat } \\
\text { kalınlıkta, kollenkima iyi } \\
\text { gelişmemiş, mezofil hücreleri } \\
\text { bulundurur. }\end{array}$ & $\begin{array}{l}\text { Mezofile göre ortalama } 3 \text { kat } \\
\text { kalınlıkta, kollenkima iyi } \\
\text { gelişmemiş, mezofil hücreleri } \\
\text { bulundurur. }\end{array}$ & $\begin{array}{l}\text { Mezofile göre ortalama } 5 \text { kat } \\
\text { kalınlıkta, kollenkima iyi } \\
\text { gelişmiş, mezofil hücreleri } \\
\text { bulundurmaz. }\end{array}$ \\
\hline $\begin{array}{l}\text { Stoma } \\
\text { dağılımı, } \\
\text { tipi }\end{array}$ & $\begin{array}{l}\text { Amfistomatik, } \\
\text { kseromorfik. }\end{array}$ & $\begin{array}{l}\text { Amfistomatik, } \\
\text { kseromorfik. }\end{array}$ & $\begin{array}{l}\text { Amfistomatik, } \\
\text { kseromorfik. }\end{array}$ \\
\hline $\begin{array}{l}\text { Yaprak } \\
\text { yüzeyi }\end{array}$ & $\begin{array}{l}\text { Epidermal hücrelerin } \\
\text { antiklinal çeperleri az veya } \\
\text { çok undulat, rafit içermez. }\end{array}$ & $\begin{array}{l}\text { Epidermal hücrelerin } \\
\text { antiklinal çeperleri az veya } \\
\text { çok undulat, rafit içermez. }\end{array}$ & $\begin{array}{l}\text { Epidermal hücrelerin } \\
\text { antiklinal çeperleri az veya } \\
\text { çok undulat, rafit içerir. }\end{array}$ \\
\hline
\end{tabular}

Perisikl tabakası altında, 4-6 sıra hücreden oluşan floem elemanı hücreler bulunmaktadır (Çizelge 2). Floemin hemen altında, floem ile ksilem arasında kambiyum tabakası bulunmaktadır. Kambiyumun çoğu preparatlarda belirgin olup birkaç tabaka küçük hücre sırasından oluştuğu görülmüştür. Kambiyumun altında trake ve 
trakeidlerden oluşan ksilem tabakası orta kısmı iri, yuvarlak veya köşeli bulunmaktadır. Ksilem elemanları arasında parankimatik hücrelerden oluşan öz tabakası öz 1şınları ayırt edilebilmektedir. Öz ışınları ile doludur.

tek sıralı ve radyal uzanımlıdır. Gövdenin
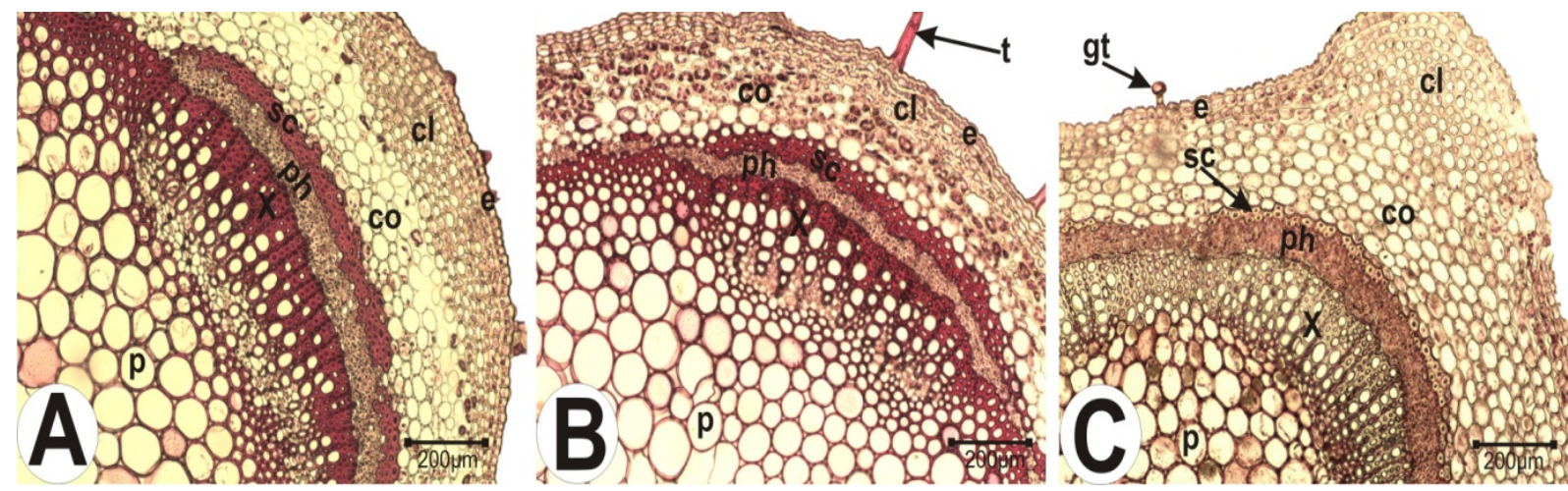

Şekil 2. Çalışılan taksonlara ait gövde enine kesitleri A: S. citrina subsp. citrina, B: S. citrina subsp. chamaesideritis, C: S. pumila, e: epidermis, t: tüy, gt: glandular tüy, cl: kollenkima, co: korteks, sc: sklerankima, ph: floem, $\mathbf{x}$ : ksilem, p:öz.

\subsection{Yaprak Anatomisi}

\subsubsection{Mezofil Anatomisi}

Enine kesitte her iki yüzeyinin de düzenli olarak sıralanmış tek sıra epidermis tabakasıyla örtülü olduğu görülmektedir. Epidermis yumurtams1, karemsi ve dikdörtgenimsi hücrelerden oluşmuş olup her iki yüzey de kalın bir kutikula tabakası ile kaplanmıştır. Alt ve üst yüzeyi saran her iki epidermis tabakası üzerinde glandular ve glandular olmayan tüyler bulunmaktadır. Glandular tüyler peltat, kısa kapitat ve uzun kapitat, glandular olmayan tüyler uzun kamçımsı, kısa ve uzun asikular (biz) şeklindedir. Kısa asikular tüyler kısa tek hücreli, uzun asikular tüyler 2-6 hücrelidir. Yaprak laminası S. pumila'da dorsiventral (bifasiyal)'dir. Yani, üst epidermisin altında oldukça iyi farklılaşmış palizat parakiması ile alt epidermisin altında bulunan sünger parankimasından oluşmaktadır. Üst epidermisin altında bulunan palizat parankiması, yaprak ayasına dikey sıralanmış silindirik hücrelerden oluşmuş olup 2-3 sira hücreden meydana gelmiştir. Yaprak mezofilinde palizat parankimasının kapladığı alan \% 60-65’tir (Çizelge 2). Palizat parankiması ile alt epidermisin arasında 2-3 sıra eni boyuna aşağı yukarı eşit olan yuvarlağımsı hücrelerden oluşmuş sünger parankiması bulunmaktadır. Sünger parankiması hücreleri arasında, daha fazla hücreler arası boşluk bulunmaktadır. $S$. pumila'dan farklı olarak S. citrina'nın her iki alt türünde de lamina, izolateral (ekvifasiyal)'dir. Yani, alt ve üst epidermanın altında palizat parankiması ve iki palizat arasında sünger parankiması bulunmaktadır. 
Palizat dokunun her iki alt türde de mezofilde kapladığı alan, \% $\quad 75-80$ civarındadır (Çizelge 2). Bununla beraber, $S$. citrina subsp. chamaesideritis'te her iki palizatı oluşturan doku hücreleri 3-4 sıralı ve küçük boyutlarda iken, S. citrina subsp. citrina'da 2-3 siralı ve daha iridirler. $S$. citrina subsp. citrina'da her iki palizat da ileri derecede farklılaşmış iken, S. citrina subsp. chamaesideritis'te alt palizat hücreleri üst palizat hücreleri kadar farklılaşmamıştır. Yani, S. citrina subsp. chamaesideritis'teki üst palizat hücrelerinin boyları enlerine göre oldukça fazla iken, alt palizat hücrelerinin boyları ile enleri arasındaki fark çok fazla değildir. Aynı şekilde, S. citrina subsp. citrina'da sünger doku belirgin şekilde farklılaşmışken, $S$. citrina subsp. chamaesideritis'te ileri derecede farklılaşma göstermemiştir.

S. citrina'nın iki alt türünde mezofil tabakası kalınlığının orta damar kalınlığına oran1 ortalama $1 / 3$ iken, S. pumila'da bu taksonda da, yaprak enine kesitinde orta damarın bulunduğu kısımda iri yapılı yarımay şeklinde bir iletim demetinin bulunduğu görülmektedir. S. pumila'da orta damarın üst epidermis ile alt epidermis altına rastlayan kesimlerinde iyi gelişmiş kollenkima tabakası vardır. Üst epidermisin altındaki kollenkima 8-11 tabakalı ve alt epidermisin altındaki kollenkima 10-12 tabakalıdır. S. citrina subsp. citrina ve $S$. citrina subsp. chamaesideritis'te ise orta damarın her iki yanındaki kollekima dokusu, S. pumila'daki kadar gelişmemiştir. Mezofil elemanı olan kloroplastlı hücreler, bu iki alt türde merkezi iletim demetinin iki yanına kadar sokulmuşlardır. İki kollenkima arasında bulunan iletim demetinde üst epidermise yönelmiş hilâl şeklinde ksilem dokusu ile onu diştan saran ve alt epidermise yönelmiş olan floem elemanları bulunmaktadır. Floem elemanlarını ise en dıştan sklerankimatik bir doku çevrelemiştir (Şekil 3).

oran 1/5’tir (Çizelge 2). Çalışılan üç

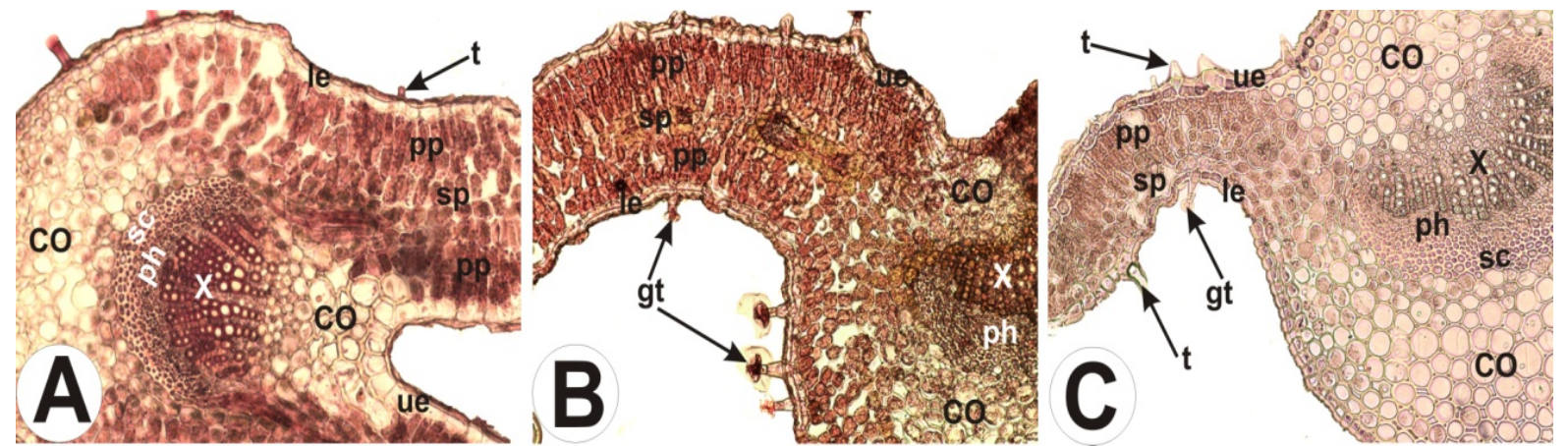

Şekil 3. Çalışılan taksonlara ait yaprak enine kesitleri A. S. citrina subsp. citrina, B. S. citrina subsp. chamaesideritis, C. S. pumila, t: tüy, le: alt epidermis, ue: üst epidermis, gt: glandular tüy, co: kollenkima, sc: sklerankima, ph: floem, x: ksilem, pp: palizat parankiması, sp: sünger parankiması. 


\subsubsection{Yaprak Yüzey Anatomisi}

Yaprak alt ve üst yüzeyinden alınan kesitlerle hazırlanan preparatlara göre, her üç taksonda da yapraklar amfistomatik olup diasitik tip stoma bulundurmaktadırlar. Stomay1 meydana getiren bekçi hücreleri, dıştan 2 epidermal hücre ile komşudur. Stomalar, her iki yüzeyde de az veya çok epidermal hücrelerden daha derinde lokalize olmuşlardır (Çizelge 2, Şekil 4). Yani kseromorfik tiptedirler. Yüzeyi çevreleyen epidermal hücrelerin antiklinal çeperleri az veya çok undulattır (dalgalı). $S$. pumila'da alt ve üst yüzey epidermal hücrelerde az miktarda rafit tip kristaller bulunmakta, S. citrina subsp. citrina ve $S$. citrina subsp. chamaesideritis'te ise bu tip kristaller bulunmamaktadır (Çizelge 2, Şekil 4).

S. citrina subsp. citrina yaprak üst yüzeyinde $\mathrm{mm}^{2}$ 'deki epidermal hücre sayısı $302 \pm 8$, stoma sayıs ise $48 \pm 5$ 'tir. Alt yüzey için stoma indeksi ise 13.71 'dir.
Yaprak alt yüzeyinde $\mathrm{mm}^{2}$, deki epidermal hücre sayıs $315 \pm 10$, stoma sayısı ise $52 \pm$ 5’tir. Alt yüzey için stoma indeksi ise $14.17^{\prime}$ 'dir. Stoma indeks oran 1 ise 0.96 'dır.

S. citrina subsp. chamaesideritis'te yaprak üst yüzeyinde $\mathrm{mm}^{2}$,deki epidermal hücre sayıs1 $294 \pm 8$, stoma sayısı ise $40 \pm$ 3’tür. Alt yüzey için stoma indeksi ise 11.97'dir. Yaprak alt yüzeyinde $\mathrm{mm}^{2}$ 'deki epidermal hücre sayıs1 $216 \pm 10$, stoma sayısı ise $44 \pm 4$ 'tür. Alt yüzey için stoma indeksi ise 16.92 ' dir. Stoma indeks oranı ise 0.71 'dir.

S. pumila'da yaprak üst yüzeyinde $\mathrm{mm}^{2}$, deki epidermal hücre sayısı $274 \pm 8$, stoma sayısı ise $20 \pm 2$ 'dir. Alt yüzey için stoma indeksi ise 6.80'dir. Yaprak alt yüzeyinde $\mathrm{mm}^{2}$, deki epidermal hücre sayısı $308 \pm 10$, stoma sayısı ise $58 \pm 5$ 'tir. Alt yüzey için stoma indeksi ise 15.84'tür. Stoma indeks oranı ise 0.43 ’tür. 

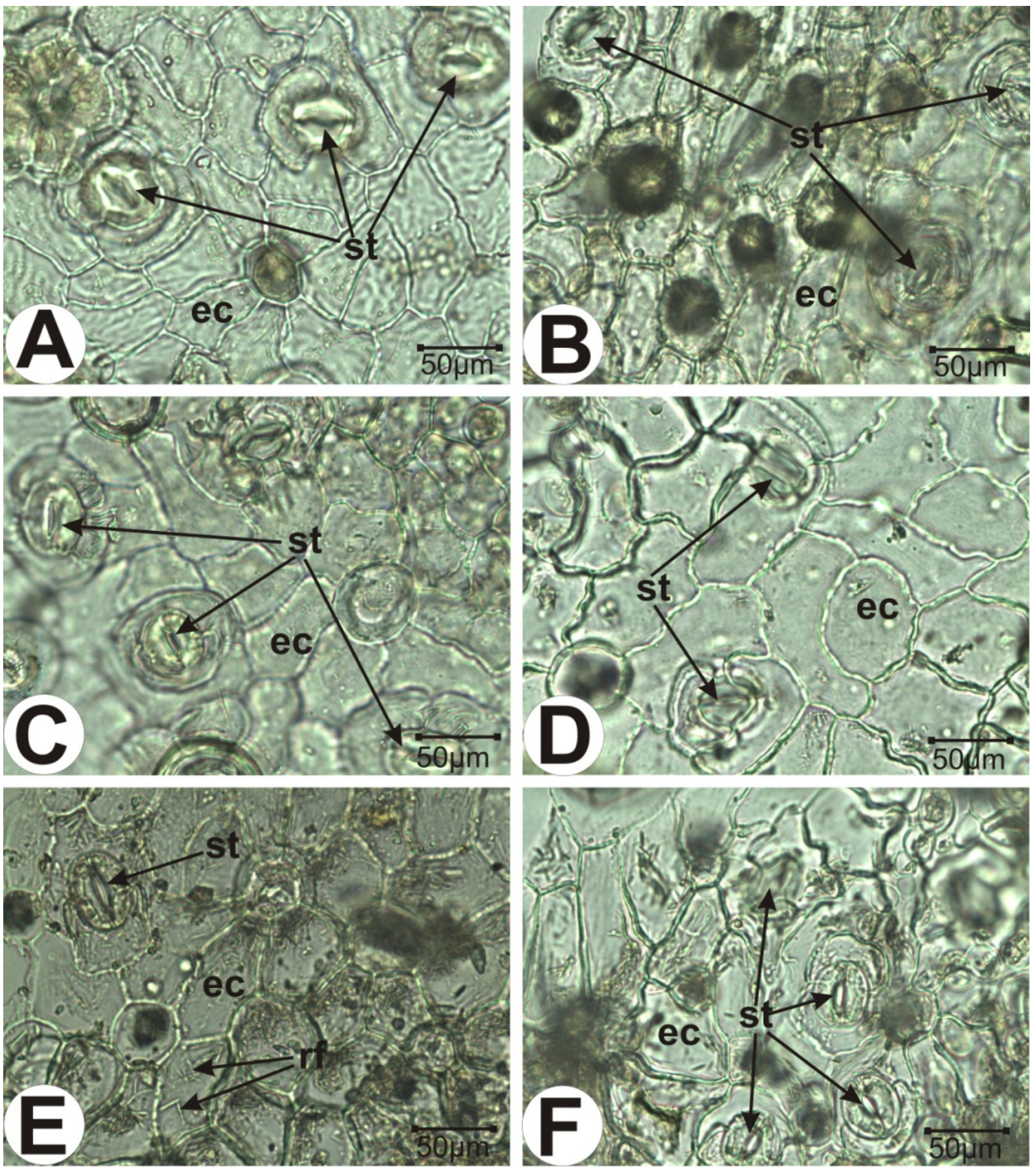

Şekil 4. Calışılan taksonlara ait alt ve üst yaprak yüzeysel kesitleri A, C, E üst yüzeysel kesitler, B, D, F alt yüzeysel kesitler, A, B S. citrina subsp. citrina, C, D S. citrina subsp. chamasderitis, E, F S. pumila ec: epidermal hücre, st: stoma, rf: rafit.

\subsection{Tüy Morfolojisi}

Çalışılan taksonlarda gövde ve yaprak üzerinde bulunan 8 tip tüy tespit edilmiştir. $\mathrm{Bu}$ tipler ve özellikleri şu şekildedir (Şekil 5):
A tipi: Bir adet bazal epidermal hücre, bir adet boyun hücresi ve 4-8 salg1 hücresinden oluşan iri başlı peltat tüyler.

B tipi: 1-2 hücreli saplı ve 1-4 salgı hücreli başa sahip olan kısa kapitat tüyler. 
C tipi: 3-5 hücreli saplı ve 1-4 salg1 hücreli başa sahip olan uzun kapitat tüyler.

D tipi: Salgısız, kalın çeperli 1 hücreli olan k1sa asikular tüyler.

E tipi: Salgısız, dallanmamış, tek sıralı dizilmiş kalın çeperli 2 hücreli olan kısa asikular tüyler.

F Tipi: Salgısız, dallanmamış, tek sıralı dizilmiş kalın çeperli 3-6 hücreli olan uzun asikular tüyler.
G Tipi: Salgısız, dallanmamış, tek sıralı dizilmiş ince çeperli 2-5-hücreli olan uzun asikular tüyler.

$\mathrm{H}$ tipi: Terminal hücreleri kırılgan, aşırı derecede uzamış, multiselular ve basit olan flagelliform (kamçımsı) tüyler.
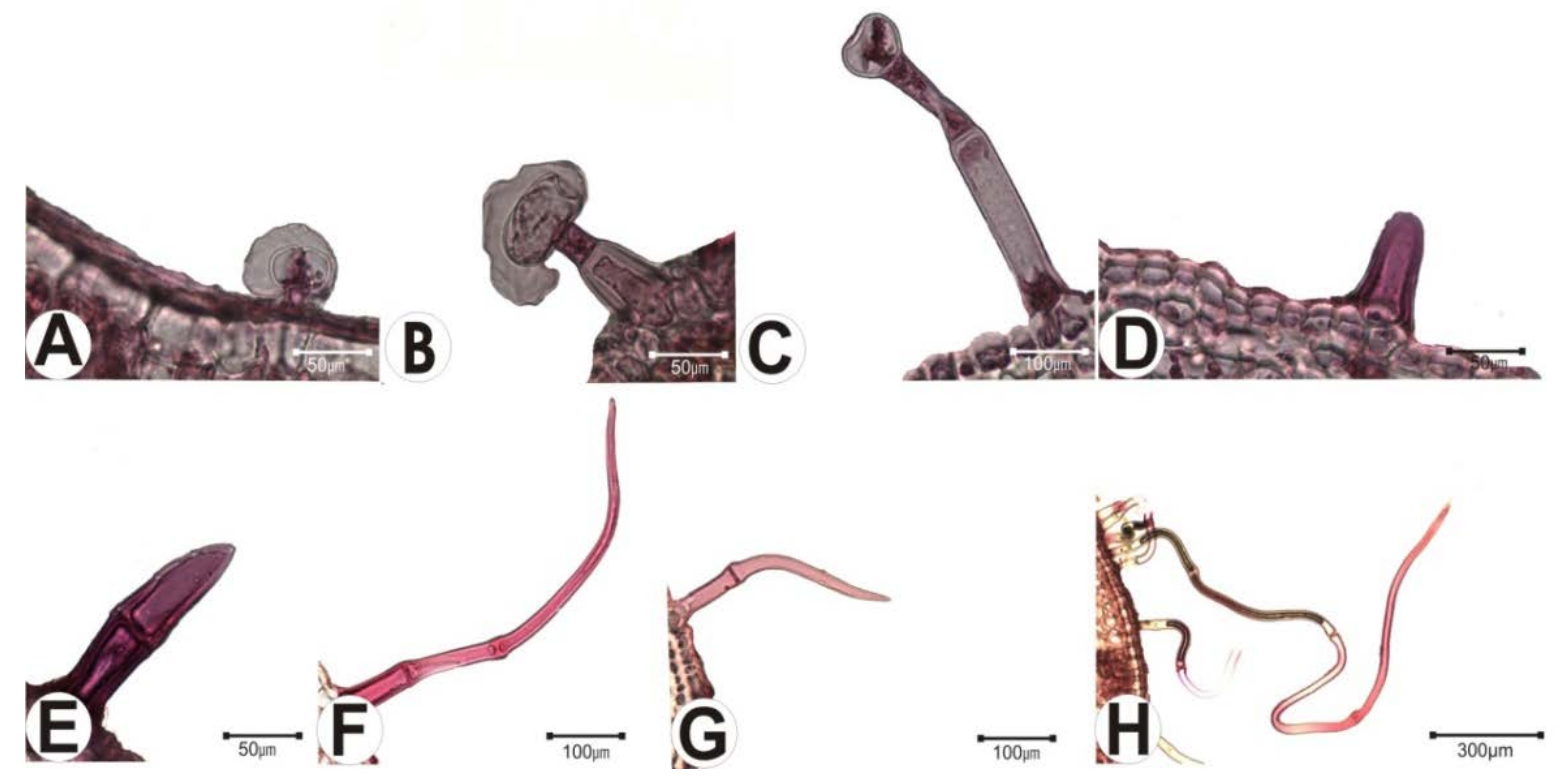

Şekil 5. Çalışılan taksonlarki tüy tipleri A. S. citrina subsp. citrina yaprağında A tipi tüy, B. S. citrina subsp. chamasderitis yaprağında B tipi tüy, C. S. citrina subsp. citrina gövdesinde C tipi tüy, D. S. citrina subsp. chamasderitis gövdesinde D tipi tüy, E. S. citrina subsp. citrina gövdesinde E tipi tüy, F. S. citrina subsp. chamasderitis gövdesinde F tipi tüy, G. S. pumila gövdesinde G tipi tüy, H. S. citrina subsp. citrina gövdesinde H tipi tüy.

S. citrina subsp. citrina'da gövdede: A, B, C, D, E, F, H tipi tüyler ve yaprakta: A, D, H tipi tüyler bulunmaktadır. S. citrina subsp. chamasderitis'te gövdede: B, D, F tipi tüyler ve yaprakta: A, B, D, F ve $\mathrm{H}$ tipi tüyler bulunmaktadır. S. pumila'da gövdede: A, B, C, D, G tipi tüyler ve yaprakta: A, B, D, H tipi tüyler bulunmaktadır (Çizelge 3). 
Çizelge 3. Çalışılan taksonlarda tüylerin gövde ve yapraktaki dağılımı

\begin{tabular}{|c|c|c|c|c|c|c|}
\hline & \multicolumn{2}{|c|}{ S. citrina subsp. citrina } & \multicolumn{2}{|c|}{ S. citrina subsp. chamasderitis } & \multicolumn{2}{|c|}{ S. pumila } \\
\hline & Gövde & Yaprak & Gövde & Yaprak & Gövde & Yaprak \\
\hline A & + & + & - & + & + & + \\
\hline B & + & - & + & + & + & + \\
\hline C & + & - & - & - & + & - \\
\hline D & + & + & + & + & + & + \\
\hline $\mathbf{E}$ & + & - & - & - & - & - \\
\hline $\mathbf{F}$ & + & - & + & + & - & - \\
\hline G & - & - & - & - & + & - \\
\hline $\mathbf{H}$ & + & + & - & + & - & + \\
\hline
\end{tabular}

\section{Tartışma}

Çalışma sonucu elde edilen verilere göre, S. pumila gövdedeki gelişmiş kollenkimatik dokusu, az gelişmiş sklerankimatik perisikl, dorsiventral (bifasiyal) yaprakları, mezofil/orta damar kalınlık oranı, yaprak epidermal hücrelerinin rafit içeriği ile S.citrina'nın alt türlerinden ayrılmaktadır. Tüy morfolojisi ve tüylerin organlara göre dağılımı taksonlar arasında bazı farklılıklar göstermektedir. S.citrina'nın alt türlerinde, kalın çeperli 3-6 hücreli olan uzun asikular tüylere rastlanırken, $S$. pumila'da ise ince çeperli 2-5 hücreli olan uzun asikular tüyler bulunmaktadır (Çizelge 2-3).

Metcalfe ve Chalk (1950), Lamiaceae familyası türlerinde, gövdenin; dört köşeli, köşelerde zengin kollenkimalı ve vasküler dokuyu çevreleyen gelişmiş sklerankimalı olduğunu vurgulamışlardır. Türkiye'deki Lamiaceae familyası türleri üzerine yapılan çalışmalarda da benzer sonuçlar elde edilmiştir (Kaya ve ark., 2000; Kandemir, 2003; Uysal, 2002, 2003; Dinç ve Öztürk, 2008a). Mevcut çalışmada Lamiaceae familyasının genel gövde anatomisine uygun sonuçlar elde edilmiştir. Şekil 2'de de görüldüğü gibi S. pumila belirgin köşeli ve köşelerde çok iyi gelişmiş kollenkimalı ve vasküler doku üstünde 2-3 sıralı sklerankima tabakasına sahip iken, S. citrina'nın alt türleri belirsiz köşeli, az gelişmiş kollenkimalı ve vasküler doku üstünde 4-6 siralı sklerankima tabakasına sahiptirler.

Lamiaceae familyasına mensup bazı türlerde yaprak mezofili ekvifasiyal iken, bazılarında bifasiyal olabilmektedirler (Uysal ve ark., 1991; Uysal, 1998; Dinç ve Öztürk, 2008a; Dinç ve ark., 2009). Mevcut çalışmada, hazırlanarak incelen bütün preparasyonlarda $S$. pumila'da yaprak mezofili ekvifasiyal iken, S. citrina'nın alt 
türlerinde bifasiyaldir. Aynı şekilde, yaprak orta damarı S. pumila'da mezofilin ortalama 5 katı kalınlıkta iken, S. citrina'nın alt türlerinde ortalama 3 katı kalınlıktadır (Çizelge 2).

$\mathrm{Bu}$ sonuç, mezofil anatomisinin yakın Stachys türlerinin ayrımında önemli olabildiğine fakat aynı türün alt türlerinde benzer olduğuna işaret etmektedir.

Infrarosularis seksiyonunun tüm üyeleri, kaya üzerinde yetişen çok yıllık kserofit türlerdir (Bhattacharjee, 1980). Yapraklardaki kalın kutikula tabakası, sünger parankimasına göre zengin palizat parankiması, stomaların derine gömülü olması (kseromorf) ve üzerlerinin güneş 1şığııı yansıtan beyaz ve yoğun tüylerle kaplı olması, kseromorfinin bazı işaretlerindendir (Metcalfe ve Chalk, 1983; Yakar ve Bilge, 1987; Öztürk ve Seçmen, 1996). Bu morfolojik ve anatomik özellikler, çalışılan her üç taksonda da görülmektedir. Bununla birlikte, S. citrina'nın alt türlerinde rastlanan geniş palizat doku, bu alt türlerin S. pumila'ya göre daha yüksek derecede ksemorfi gösterdiğine işaret etmektedir.

Metcalfe ve Chalk'a göre, basit kristaller ve druzlar dikotiledonlar arasında en yaygin kristal tipleri iken, sferokristaller ve rafitler nadir rastlanan tiplerdir ve taksonomik değere sahiptirler (Dinç ve ark.,
2009). Nitekim Teucrium seksiyonundan olan Teucrium creticum ve $T$. sandrasicum'un epidermal hücrelerinde sferokristallere rastlanırken, aynı seksiyondan olan T. orientale'de rastlanmamaktadır (Dinç ve ark., 2008b; 2009). Çalışılan taksonlardan S. pumila'nın yaprak epidermal hücrelerinde rafitlere rastlanması, S. citrina'nın alt türlerinde rastlanmaması, bu kristallerin diagnostik değerini doğrulamakta ve yapılacak taksonomik çalışmalarda dikkate alınması gerektiğini göstermektedir.

Stachys sect. Ambleia'nın Türkiye'deki türleri üzerine yapılan tüy morfolojisi çalışmaları, bu seksiyondaki Stachys cydni ve S. yildirimlii türlerinin tüy morfolojisi bakımından ayrıldığını net olarak göstermiştir (Dinç ve Öztürk, 2008a). Çalışılan taksonlardan S. pumila'daki 2-5 hücreli uzun asikular tüyler, ince çeperli ve yumuşak iken S. citrina'nın alt türlerinde 26 hücreli asikular tüyler kalın çeperli, sert ve kirılgandir.

Çalışmadan elde edilen sonuçlar, anatomik karakterler ve tüy morfolojisi karakterlerinin, yakın akraba türler olan $S$. citrina ile $S$. pumila'nın taksonomik sınıflandırılmasında değere sahip olduğunu, fakat S. citrina'nın alt türlerinin ayrımında değerlerinin sınırlı olduğunu göstermiştir. 


\section{Kaynaklar}

Abu Assab S, Cantino PD (1987). Phylogenetic implications of leaf anatomy in subtribe Melittidinae (Labiatae) and related taxa. Journal of the Arnold Arboretum 68: 1-34.

Akçiçek E (2010). A new subspecies of Stachys cretica (section Eriostomum, Lamiaceae) from Turkey. Turkish Journal of Botany 34: 131-136.

Akçiçek E (2012). Stachys. Güner A, Aslan S, Ekim T, Vural M ve Babaç MT (edlr.) Türkiye Bitkileri Listesi (Damarlı Bitkiler). Nezehat Gökyiğit Botanik Bahçesi ve Flora Araştırmaları Derneği Yayını. İstanbul.

Baran P, Özdemir C (2009). The morphological and anatomical properties of Lamium lycium (Lamiaceae) endemic to Turkey. Nordic Journal of Botany 27: 388-396.

Bhattacharjee R (1980). Taxonomic Studies in Stachys II, A new infrageneric classification on Stachys L. Notes from the Royal Botanic Garden Edinburg 38: 65 - 96.

Bhattacharjee R (1982) Stachys L. Davis, P.H. (ed.), Flora of Turkey and East Aegean Islands, Edinburgh University Pres. Edinburgh 19, vol. 7: 199-262.

Bini Maleci L, Servettaz O (1991). Morphology and distribution of trichomes in Italian species of Teucrium sect. Chamaedrys (Labiatae) - a taxonomical evaluation. Plant Systematic and Evolution 174: 83-91.

Daşkın R, Yılmaz Ö, Kaynak G (2009). Stachys ketenoglui sp. nov. (sect. Infrarosularis) (Labiatae/Lamiaceae) from south Anatolia Turkey. Nordic Journal of Botany 27: 238242.

Davis PH, Mill RR, Tan K (1988). Stachys L. - In: Davis PH, Mill RR ve Tan K (eds.). Flora of Turkey and East Aegean Islands (Subpl. 1), Edinburgh University Pres, vol. 10: 204206.

Demirelma H, Kırıcı ÜG, Çıtak BY (2018). An anatomical investigation on Sideritis ozturkii Aytaç \& Aksoy and Sideritis rubriflora Hub.- Mor. (Lamiaceae) from Turkey. Biological Diversity and Conservation 11: 153-158.

Dinç M, Doğan HH (2006). Stachys yildirimlii (Lamiaceae), a new species from south Anatolia, Turkey. Annales Botanici Fennici 43: 143-147.

Dinç M, Öztürk M (2008a). Comparative morphological, anatomical, and palynological studies on the genus Stachsy L. sect. Ambleia Bentham (Lamiaceae) species in Turkey. Turkish Journal of Botany 32: 113-121.

Dinç M, Duran A, Pınar M, Öztürk M (2008b). Anatomy, palynology and nutlet micromorphology of Turkish endemic Teucrium sandrasicum (Lamiaceae). Biologia 63/5: 637-641.

Dinç M, Doğu S, Bilgili B, Duran A (2009). Comparative anatomical and micromorphological studies on Teucrium creticum and Teucrium orientale var. orientale (T. sect. Teucrium, Lamiaceae). Nordic Journal of Botany 27: 251-256.

Dinç M, Doğu S, Doğru Koca A, Kaya B (2011). Anatomical and nutlet differentiation between Teucrium montanum and T. polium from Turkey. Biologia 66: 448-453.

Duman H (2000). Stachys L. - In: Güner, A., Özhatay, N., Ekim, T. ve Başer, K.H.C. (eds.), Flora of Turkey and East Aegean Islands (subpl. 2). Edinburgh University Press, Edinburgh, vol. 11: 204-206. 
Duman H, Kırımer N, Ünal F, Güvenç A, Şahin PF (2005). Türkiye Sideritis L. Türleri’nin Revizyonu, Ankara, Proje No: TBAG-1853 (199T090).

Özcan M, Ağaoğlu E (2014). Stem and leaf anatomy of three taxa in Lamiaceae. Bangladesh Journal of Botany 43: 345-352.

Güvenç A, Duman H (2010). Morphological and anatomical studies of annual taxa of Sideritis L. (Lamiaceae), with notes on chorology in Turkey. Turkish Journal of Botany 34: 83-104.

İlçim A, Çenet M, Dadandı MY (2008). Stachys marashica (Lamiaceae), a new species from Turkey. Annales Botanici Fennici 45: 151-155.

Kahraman A, Celep F, Doğan M (2009). Morphology, anatomy and palynology of Salvia indica (Labiatae). World Applied Sciences Journal 6: 289-296.

Kahraman A, Doğan M, Celep F, Akaydın G, Koyuncu M (2010a). Morphology, anatomy, palynology and nutlet micromorphology of the rediscovered Turkish endemic Salvia ballsiana (Lamiaceae) and their taxonomic implications. Nordic Journal of Botany 28: 91-99.

Kahraman A, Celep F, Dogan M (2010b). Morphology, anatomy, palynology and nutlet micromorphology of Salvia macrochlamys (Labiatae) in Turkey. Biologia 65 (2): 219227.

Kandemir N (2003). The morphological, anatomical and karyological properties of endemic Salvia hypargeia Fich. ve Mey. (Lamiaceae) in Turkey. Pakistan Journal of Botany 35: 219-236.

Kaya A, Başer KHC, Satıl F, Tümen G (2000). Morphological and anatomical studies on Cyclotrichium origanifolium (Labill.) Manden. ve Scheng. (Labiatae). Turkish Journal of Botany 24: 273-278.

Meidner H, Mansfield TA (1968). Physiology of stomata, Graw-Hill, New York.

Metcalfe CR, Chalk L (1950). Anatomy of the Dicotyledons Oxford Vol.1, Oxford University Pres, 810-816.

Metcalfe CR, Chalk L (1972). Labiatae, pp. 1041-1053. In: Metcalfe C.R. ve Chalk L. (eds), Anatomy of the dicotyledons, Vol. II, Oxford University Press, Oxford.

Metcalfe CR, Chalk L (1983). Anatomy of the Dicotyledons II., London.

Mihalik E (1992). Histological detection of sudanophilic lipits in some Lamiaceae. Acta Horticulturae 306: 259-267.

Navarro T, El Oualidi J (2000). Trichome morphology in Teucrium L. (Labiatae), a taxonomic review. Anales Jardin Botanico De Madrid 57: 277-297.

Özdemir C, Şenel G (1999). The morphological, anatomical and karyological properties of Salvia sclarea L. Turkish Journal of Botany 23: 7-18.

Özdemir C, Şenel G (2001) . The morphological, anatomical and karyological properties of Salvia forskahlei L. (Lamiaceae) in Turkey. Journal of Economic and Taxonomic Botany 19: 297-313.

Özörgücü B, Gemici Y, Türkan İ (1991). Karşılaştırmalı Bitki Anatomisi. Ege Üniversitesi, Bornova, İzmir.

Öztürk M, Seçmen Ö (1996). Bitki Ekolojisi, Ege Üniversitesi Basımevi. Bornova-İzmir, 238. 
Payne Wilfred W (1978). A glossary of plant hair terminology. Brittonia 30: 239-255.

Satıl F, Kaya A (2007). Leaf anatomy and trichomes of Turkish Satureja L. (Lamiaceae). Acta Biologica Cracoviensia Series Botanica 49: 67-76.

Satıl F, Kaya A, Dirmenci T (2011). The taxonomic value of leaf anatomy and trichome morphology of the genus Cyclotrichium (Lamiaceae) in Turkey. Nordic Journal of Botany 29: 38-48.

Uphoff JCT (1962). Plant hairs, pp. 136-250. In: Zimmermann W. \& Ozenda P.G. (eds), Encyclopedia of plant anatomy, IV (5), Gebruder Borntraeger, Berlin-Nikolassee.

Uysal İ, Öztürk M, Pirdal M (1991). Sidertis trojana Bornm. endemik türünün morfolojisi, anatomisi ve ekolojisi. Doğa Botanik Dergisi 15: 371-379.

Uysal İ (1998). Stachys thirkei C. Koch türünün morfolojisi, anatomisi ve ekolojisi üzerinde incelemeler. II. Kızılırmak Uluslararası Fen Bilimleri Kongresi Bildirileri. Kırıkkale.

Uysal İ (2002). Stachys cretica L. subsp. smyrnaea Rech Fil. Endemik taksonunun morfolojisi, anatomisi ve ekolojisi üzerinde araştırmalar. Ekoloji 11: 16-20.

Uysal İ (2003). Stachys thirkei C.Koch (Kekikgiller) türünün morfolojisi, anatomisi ve ekolojisi üzerine araştırmalar. Ot Sistematik Botanik Dergisi 10: 129-141.

Vardar Y (1987). Botanikte Preparasyon Tekniği. Ege Üniversitesi Fen Fakültesi Basımevi, Izmir.

Yakar N, Bilge E (1987). Genel Botanik (üçüncü baskı). İstanbul Üniversitesi Fen Fakültesi Yayınları. Rektörlük No: 3438, Fakülte No:200 İstanbul.

Yılmaz Ö, Daşkın R, Kaynak G (2010). Stachys pseudobombycina sp. nov. (Lamiaceae) from South Anatolia, Turkey. Nordic Journal of Botany 28: 341-343. 